\title{
Associations between Obesity and Sleep Quality among Older Adults in a Health Center in Iran
}

\author{
Maryam Baradaran-Binazir ${ }^{1}$, Kolsoom Masoumi ${ }^{2}$, Fatemeh Hobbi ${ }^{2}$ and Fariba Heidari ${ }^{1}$ \\ ${ }^{1}$ Social Determinants of Health Research Center, Health Management and Safety Promotion Research Institute, Tabriz University of Medical Sciences, \\ Iran \\ ${ }^{2}$ Ebne Sina health center, Tabriz University of Medical Sciences, Iran
}

Submission: February 22, 2021; Published: March 10, 2021

*Corresponding author: Maryam Baradaran-Binazir, Faculty of Medicine, Social Determinants of Health Research Center, Health Management and Safety Promotion Research Institute, Tabriz University of Medical Sciences, Golgasht Ave.

Abstrcat

The major aim of this investigation was to assess the relationships between sleep duration and sleep quality with overweight or obesity in a sample of older adults in Tabriz, Iran. In a cross-sectional study 310 older adults (55.7\% of women) were completed Pittsburgh Sleep Quality Index (PSQI) questionnaire. It was designed to assess sleep duration and sleep quality. Body-mass index (BMI) was measured and dichotomized as normal and overweight or obesity status. The mean age (SD) of participants was 65.9(3.1) years. More than $30 \%$ of participants were overweight or obese. The findings of the current study demonstrated statistically significant relationships between sleep duration and sleep quality with BMI. Appropriate acts and approaches that contain both sleep duration and sleep quality as guarding factors against overweight or obesity are recommended.

Keywords: Overweight or obesity; Body-mass index; Coronary artery diseases; Musculoskeletal; Metabolic disorders; Sleep quality

Abbreviations: PSQI: Pittsburgh Sleep Quality Index; BMI: Body-Mass Index; SD: Mean Age

\section{Introduction}

Obesity and overweight have turn into one of the major public health challenges throughout the world in the recent years [1]. It has been established that obesity and overweight in the community are risk factors for coronary artery diseases, musculoskeletal, and metabolic disorders [2]. One investigation has demonstrated that the prevalence of obesity and overweight in communities has increased quickly, especially in high and middle-income countries [3].

In addition, more consideration has been given to sleep period [4] and sleep quality [5] related to BMI, recently. Findings from these investigations were contradictory. Even though, some investigations demonstrated a negative relationship between sleep duration and BMI (Body Mass Index) [6], other studies showed U-shaped [4] or yet no relationship [7].

The older adults are at great risk, because it goes by way of habits modifications with regard to vast urbanization, which may possibly cause inadequate sleep and impaired sleep quality
[8], generally occurred with poor daily intake of food [9] and absence of exercise [10]. The association between extended sleep time and higher BMI is uncertain. Former investigations done on younger adults showed that who had extended sleep time had more probability for becoming overweight or obese [4]. It was reported who had extended sleep time exercise lesser, which can conceivably decrease energy consumption [11]. Based on the above-mentioned, there was no study investigating relationships between sleep time and sleep quality with Obesity and overweight in older adults. So, the major goals of this investigation were to study associations between sleep time and quality with BMI status in a sample of older adults.

We conducted a cross-sectional study among older adults in Ebnesina health center in Tabriz, the largest city in northwest of Iran, in May 2019. To study sleeping habits, we applied Pittsburgh Sleep Quality Questionnaire (PSQI), a reliable and valid questionnaire to evaluate sleep quality [8]. It has 19 items and included 7 main factors. Each factor was graded from 0 to 3 points, 
in that lower point indicated no dilemmas, while higher score indicated worsening dilemmas [8]. All 7 factors were summed up to calculate a total score 0 to 21 points. Then, the total scores were dichotomized into two groups: 5 and less than 5 (proper sleep quality), but more than 5 (poor sleep quality) [8]. Participants completed the questionnaires with helps of health provider in the health center. Simultaneously, the health providers measured their height in meters (m) and weight in kilograms (kg) in order to calculate BMI. Subsequently, the BMIs were dichotomized into two categories: normal if BMI was less than 25 and overweight/ obesity if the BMI was 25 or more.

Totally, 310 older adults participated in this study. More than half of them were female (55.7\%). The mean age (SD) of participants was $65.9(3.1)$ years. More than $30 \%$ of participants were overweight or obese. Associations among categorical variables were analyzed using Chi-square test (Table 1).

Table 1: Association of sleep duration and sleep quality with BMI among 310 older adults, using Chi-square test.

\begin{tabular}{|c|c|c|c|}
\hline Variables & Normal BMI N (\%) & Overweight/Obesity N (\%) & P Value \\
\hline Sleep duration & & & $12(10.1)$ \\
\hline $6 \mathrm{~h}>$ & $51(25.2)$ & $96(89.9)$ & 0.002 \\
\hline $6 \mathrm{~h} \leq$ & $151(74.8)$ & & \\
\hline Sleep quality & & $57(52.7)$ & \\
\hline Proper & $163(80.6)$ & $51(47.3)$ & $<0.001$ \\
\hline Poor & $39(19.4)$ & & \\
\hline
\end{tabular}

\section{Conclusions}

The findings of the current study demonstrated relationships between sleep duration and sleep quality with BMI.

\section{Acknowledgement}

We deeply appreciate all older adults in Ebnesina health center participated in this study.

\section{References}

1. World Health Organization (2004) Global strategy on diet, physical activity and health.

2. Berrington de Gonzalez A, Hartge P, Cerhan JR, Flint AJ, Hannan L, et al. (2010) Body-mass index and mortality among 1.46 million white adults. N Engl J Med 363(23): 2211-2219.

3. Abarca-Gómez L, Abdeen ZA, Hamid ZA, Abu-Rmeileh NM, AcostaCazares B, et al. (2017) Worldwide trends in body-mass index, underweight, overweight, and obesity from 1975 to 2016: a pooled analysis of 2416 population-based measurement studies in 128. 9 million children, adolescents, and adults. Lancet 390(10113): 26272642.
4. Wu J, Wu H, Wang J, Guo L, Deng X, et al. (2015) Associations between sleep duration and overweight/obesity: results from 66,817 Chinese adolescents. Sci Rep. 5(1): 1-10.

5. Peltzer K, Pengpid S (2017) Sleep duration, sleep quality, body mass index, and waist circumference among young adults from 24 lowand middle-income and two high-income countries. Int J Environ Res Public Health 14(6): 566.

6. Meyer K A, Wall M M, Larson N I, Laska M N, Neumark-Sztainer D (2012) Sleep duration and BMI in a sample of young adults. Obesity (Silver Spring) 20(6): 1279-1287.

7. Krističević T, Štefan L, Sporiš G (2018) The associations between sleep duration and sleep quality with body-mass index in a large sample of young adults. Int J Environ Res Public Health 15(4): 758.

8. Pelletier J E, Graham D J, Laska M N (2014) The associations between sleep duration and sleep quality with body-mass index in a large sample of young adults. Am J Health Behav 38(1): 144-152.

9. Keating X D, Guan J, Piñero J C, Bridges D M (2005) A meta-analysis of college students' physical activity behaviors. J Am Coll Health 54(2): 116-126.

10. Ayas N T, White D P, Manson J E, Stampfer M J, Speizer F E, et al. (2003) A prospective study of sleep duration and coronary heart disease in women. Arch Intern Med 163(2): 205-209. 
CC This work is licensed under Creative Commons Attribution 4.0 Licen DOI: 10.19080/CRDOJ.2021.14.5584

\begin{tabular}{l} 
Your next submission with Juniper Publishers \\
will reach you the below assets \\
- Quality Editorial service \\
- Swift Peer Review \\
- Reprints availability \\
- E-prints Service \\
- Manuscript Podcast for convenient understanding \\
- Global attainment for your research \\
- Manuscript accessibility in different formats \\
( Pdf, E-pub, Full Text, Audio) \\
- Unceasing customer service \\
Track the below URL for one-step submission \\
https://juniperpublishers.com/online-submission.php \\
\hline
\end{tabular}

